\title{
Refractory Lymphoblastic Lymphoma
}

National Cancer Institute

\section{Source}

National Cancer Institute. Refractory Lymphoblastic Lymphoma. NCI Thesaurus. Code C151978.

Lymphoblastic lymphoma that is resistant to treatment. 